\title{
ASSESSMENT OF RISK FACTORS FOR PRIMARY POSTPARTUM HEMORRHAGE AT ZAGAZIG UNIVERSITY HOSPITALS
}

\author{
Amal A. El Badawy ${ }^{1}$, Eman H. Waly ${ }^{1}$, Nahla M. Zaitoun ${ }^{1}$, and Youssef Abo-Elwan ${ }^{2}$ \\ ${ }^{1}$ Public Health and Community Medicine Department, Faculty of Medicine, Zagazig University, Zagazig, \\ Sharkia, Egypt \\ ${ }^{2}$ Obstetrics and Gynecology Department, Faculty of Medicine, Zagazig University, Zagazig, Sharkia, Egypt
}

Corresponding author:

Eman Hasan Waly

Email:

eman_waly78@yahoo.com

Mobile: 00966541103810

\begin{abstract}
Background: Primary postpartum hemorrhage PPH is a major cause of maternal morbidity and mortality. Many risk factors for primary PPH have been evaluated, while with changes of obstetric population and technological advances, some of these factors became more important and others were less. Aim: To identify common risk factors of primary PPH and measure the association between these factors and the occurrence of primary PPH. Methods: A case control study was conducted in obstetrics and gynecology department at Zagazig University Hospitals. Participants were selected by systematic random sampling. Data were collected about the participants' age and social class as well as studied risk factors for primary $\mathrm{PPH}$ including previous delivery mode, previous antipartum hemorrhage APH, previous $\mathrm{PPH}$, parity, birth weight, gestational age, maternal obesity, maternal hemoglobin level, labor induction, current delivery mode, delivery trauma, episiotomy, placenta previa and retained placenta. Results: Primary PPH was significantly higher among older ages (> 34 years). Primary PPH showed significant associations with the following factors; Previous APH $(\mathrm{OR}=3.57)$, previous $\mathrm{PPH}(\mathrm{OR}=2.85)$, macrosomia $(\mathrm{OR}=9.57)$, maternal anemia $(\mathrm{OR}=5.37)$, obesity $(\mathrm{OR}=4.01)$, vaginal delivery $(\mathrm{OR}=2.13)$, labor induction $(\mathrm{OR}=2.88)$, trauma $(\mathrm{OR}=3.53)$, retained placenta $(\mathrm{OR}=8.51)$, and placenta previa $(\mathrm{OR}=3.51)$. Conclusion: Maternal anemia, retained placenta, Macrosomia, and previous $\mathrm{PPH}$ were the most significant risk factors for primary $\mathrm{PPH}$. Recommendations: Organized antenatal visits are recommended to help early detection of PPH risk factors and improve females' knowledge about PPH risk. clinicians should optimize care for high risk women. Adequate supplies should be provided to health facilities for prompt management of PPH.

Running header: Risk Factors for Primary Postpartum Hemorrhage

Key words: Postpartum hemorrhage, Risk factors, Pregnant, Zagazig
\end{abstract}

\section{INTRODUCTION}

$\mathrm{P}$ ostpartum hemorrhage (PPH) is a major cause of maternal mortality and severe morbidity all over the world. "1] The World Health Organization (WHO) estimates that, $\mathrm{PPH}$ is a cause of approximately $25 \%$ of maternal deaths. ${ }^{[2]}$ Recently, the industrialized countries have witnessed a slow but steady escalation in the incidence of $\mathrm{PPH} .{ }^{[1]}$

Traditionally, PPH has been defined as blood loss of $500 \mathrm{ml}$ or more after vaginal delivery or $1000 \mathrm{ml}$ or more after cesarean delivery. ${ }^{[3]}$ Primary PPH occurs within 24 hours of delivery and secondary PPH occurs after 24 hours and within 6 weeks of delivery. ${ }^{[4]}$ Another definition of $\mathrm{PPH}$ is decline in hematocrit value by $10 \%$ between the antenatal and postpartum periods. ${ }^{[5]}$ Also, PPH was defined as the need for red blood cell transfusion because of maternal anemia or hemodynamic instability. ${ }^{[6]}$

low-resource developing countries experience a much higher burden of $\mathrm{PPH}$, it is also a momentous cause of maternal death in the developed world. ${ }^{[7]}$ Death from PPH occurs in about 1 per 1000 deliveries in low-resource countries compared with 1 per 100,000 deliveries in high-resource countries. ${ }^{[8]}$ 
Globally, PPH causes 44,000 to 86,000 deaths per year considering it the leading cause of death in pregnancy. ${ }^{[9]}$ Even though maternal deaths are lesser in high resource countries, the morbidity accompanied with severe $\mathrm{PPH}$ is considered a major problem. ${ }^{[10]}$

Risk factors of PPH are important and should be studied even though up to $66 \%$ of cases of PPH had no identifiable risk factors. ${ }^{[5]}$ The most common risk factors for $\mathrm{PPH}$ are poor uterine contraction following childbirth, retained placenta, uterine tears, or poor clotting of blood. It occurs more commonly in the anemic women, multiparity, obese or old aged women (> 40 years), with macrosomia. ${ }^{[11]}$ Clinicians should try to identify risk factors antenatally and during labor in order to deliver high risk women at the highest level of care. ${ }^{[12]}$

Therefore, our objectve in this study was to identify common risk factors of primary $\mathrm{PPH}$ and measure the association between the studied risk factors and the occurrence of primary PPH.

\section{PATIENTS AND METHODS}

The study design and setting: The study was carried out as a case control study over a period of five months; from June 2013 to October 2013 in obstetrics and gynecology department at Zagazig university hospitals.

Study Population and Sampling: The target population included females in last trimester of pregnancy of any age group were admitted to hospital for vaginal or cesarean section (CS) delivery. Assuming that the lowest prevalent risk factor is retained placenta $(10.6 \%)$, with an odds ratio of $4.2,{ }^{[13]}$, the estimated sample size in each case and control group was 59 pregnant females (total sample size 118) calculated by Epi- info program version 6 with a confidence interval $95 \%$ and $80 \%$ as the power of test. Our participants were selected by the systematic random sampling technique. Listing of females coming in labor was done two days per week then in those days every $4^{\text {th }}$ female fulfilling the inclusion criteria was chosen after a random starting point.

\section{Inclusion criteria:}

The case group: Females showing the clinical diagnosis of primary PPH who were admitted to the hospital for vaginal or cesarean section delivery in last trimester of pregnancy of any age and parity (nullipara, 1-3 previous para, or $>3$ previous para). Primary $\mathrm{PPH}$ was defined as: estimated blood loss of $500 \mathrm{ml}$ or more after vaginal delivery and $1000 \mathrm{ml}$ or more for a cesarean delivery, ${ }^{[3]}$ or requirement for blood cell transfusion due of maternal anemia or hemodynamic instability. ${ }^{[6]}$ Admission and postdelivery hematocrit values were not obtained on all admissions therefore, the criteria that were used in this study for PPH were the measured blood loss and need for blood transfusion. The control group: Females who were admitted to hospital for vaginal or cesarean section delivery in last trimester of pregnancy of any age and parity and and not suffered from primary $\mathrm{PPH}$ during labor.

\section{Exclusion criteria:}

Females were excluded if they had a condition introducing an indication or confounding bias in the association between induction of labor and $\mathrm{PPH}$ as prenatal chronic disease or coagulopathy as well as the females with pregnancy induced diseases as gestational diabetes and preeclampsia and those taking anti-coagulant drugs during pregnancy. Also, Women were diagnosed with secondary $\mathrm{PPH}^{[4]}$ were excluded from the study.

Data collection: A structured questionnaire was used to collect data regarding the participants' socio-demographic characteristics as well as some risk factors for PPH. The sociodemographic data included age and social class (social class was classified as low class $<50 \%$, moderate class $\geq 50-75 \%$, high class $\geq 75 \%$ ). ${ }^{[14]}$ Data about risk factors for $\mathrm{PPH}$ that were considered in the study included; a) Previous obstetric related factors: previous delivery mode (vaginal or cesarean section) and previous antipartum or postpartum haemorrhage (APH or $\mathrm{PPH}$ ). b) Current obstetric related factors: parity (nullipara, 1-3 previous para, and $>3$ previous para), Birth 
weight (low birth weight $<2500 \mathrm{~g}$, normal weight, and Macrosomia $\geq 4,000 \mathrm{~g}),{ }^{[15]}$ gestational age (preterm birth $<37$ weeks, term pregnancy from 37 to 41 weeks, and post-term pregnancy > 41 weeks), maternal Body Mass Index BMI (considering $<18$ is under weight, from 18 to $\leq 25$ is normal weight, from 25 to $\leq$ 30 is overweight, and > 30 is obese),${ }^{[6]}$ and maternal hemoglobin $\mathrm{Hb}$ level (complete blood count is done before and after cesarean section in hospital and in case of vaginal delivery it is done for cases that exposed to PPH and if not exposed to PPH it depends on that they had done it during their antenatal care). c) Delivery related factors: induction of labor, delivery mode, trauma (cervical, vaginal, and perineal tears), episiotomy, placenta previa and retained placenta.

Ethical consideration and administrative approach: To carry out the study the necessary official permissions were taken from the heads of obstetrics and gynecology department and outpatient clinic at Zagazig University Hospitals. An informed written consent was obtained from the participants and they were reassured about the confidentiality of information and the results were used for the purpose of the scientific research and they were also given the right to refuse or participate in the study.

Pilot study: A pilot study was conducted before starting data collection which involved 10 females, five cases and five controls admitted to hospital for delivery and were not included in the study to test the clarity and applicability of the questionnaire and necessary modifications were made accordingly.

Statistical Analysis: Statistical analysis was conducted using SPSS software version 19.0. Qualitative data were represented as frequencies and relative percentages and chi square test was used to calculate significant differences among sociodempgraphic characterisics of both case and control groups.
Odd's Ratio (OR) and their 95\% confidence intervals $(95 \% \mathrm{CI})$ were calculated to compare risk factors for PPH in both groups. Stepwise logistic regression analysis was performed for all significant risk factors affecting PPH.

\section{RESULTS}

The total number of women included in the study was 118 . Most of them were in the age group 19-34 years (81.4\% of cases and $66.1 \%$ of controls) and primary PPH was significantly higher among older ages (> 34 years) (Figure $1)$. The majority of paticipants were of low social class $(69.5 \%$ of cases and $79.7 \%$ of controls) (Figure 2).

Table I showed a statistical significant association between primary $\mathrm{PPH}$ and previous and current obstetric related factors. The females with previous history of APH and PPH had an increased risk for current PPH by more than three folds $(\mathrm{OR}=3.57)$ and two folds $(\mathrm{OR}=2.85)$ respectively. Also, macrosomia, maternal anemia, and maternal obesity were considered highly statistical significant risks for primary $\mathrm{PPH}$ with increased risk by more than nine folds $(\mathrm{OR}=9.57)$, five folds $(\mathrm{OR}=5.37)$, and four folds $(\mathrm{OR}=4.01)$ respectively.

Regarding the delivery factors and occurrence of primary $\mathrm{PPH}$; the vaginal delivery and induction of labor showed significant increased risks for PPH by more than two folds with the following odds ratios $(\mathrm{OR}=2.13$ and $\mathrm{OR}=2.88)$ respectively, and delivery trauma showed significant increased risk for PPH by more than three folds $(\mathrm{OR}=3.53)$. Also, both retained placenta and placenta previa were considered significant risk factors for PPH with increased risk by more than eight folds $(\mathrm{OR}=8.51)$, and three folds $(\mathrm{OR}=3.51)$ respectively (Table II). Stepwise logistic regression analysis of significant risk factors revealed that, maternal anemia, retained placenta, macrosomia, and previous $\mathrm{PPH}$ were the most statistical significant risk factors of PPH (Table III). 


\section{Figures and tables}

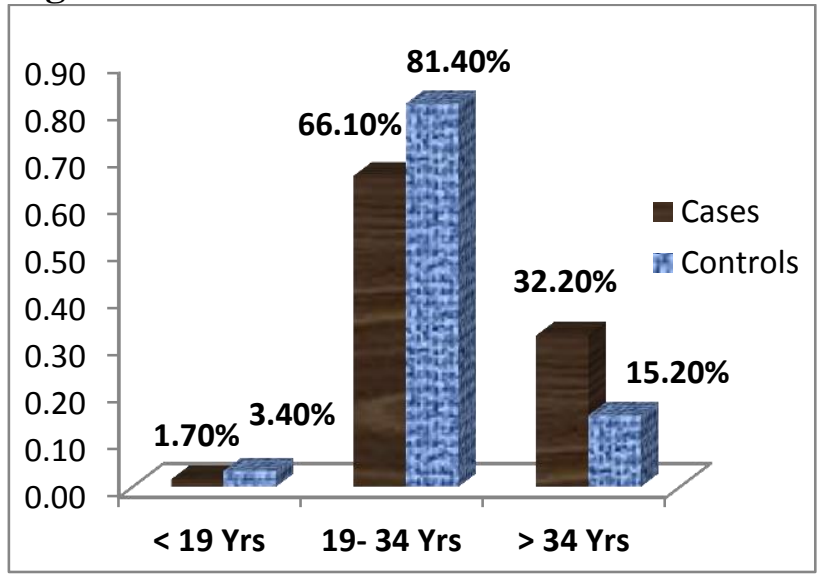

Figure I: $\mathrm{PPH}$ with age groups of participants $(P=0.03)$

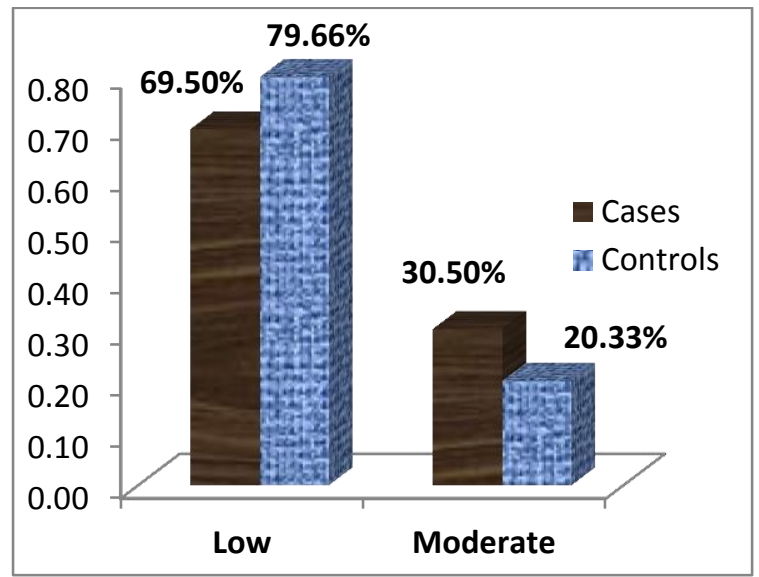

Figure II: $\mathrm{PPH}$ with participants' social class $(P=0.2)$

Table I: Association of primary PPH with previous and current obstetric related factors

\begin{tabular}{|c|c|c|c|c|}
\hline Risk factors & $\begin{array}{c}\text { Cases } \\
59(\%)\end{array}$ & $\begin{array}{l}\text { Control } \\
59(\%)\end{array}$ & $\mathbf{P}$ & OR $(95 \% \mathrm{CI})$ \\
\hline \multicolumn{5}{|l|}{ Previous cesarean section } \\
\hline Yes $(N=37)$ & $23(38.9)$ & $14(23.7)$ & 0.076 & $2.05(0.93-4.56)$ \\
\hline No $(\mathrm{N}=81)$ & $36(61.1)$ & $45(76.3)$ & & \\
\hline \multicolumn{5}{|l|}{ Previous APH } \\
\hline Yes $(N=23)$ & $17(28.8)$ & $6(10.2)$ & $0.01^{*}$ & $3.57(1.29-9.86)$ \\
\hline No $(\mathrm{N}=95)$ & $42(71.2)$ & $53(89.8)$ & & \\
\hline \multicolumn{5}{|l|}{ Previous PPH } \\
\hline Yes $(N=29)$ & $20(33.9)$ & $9(15.3)$ & $0.02^{*}$ & $2.85(1.17-6.95)$ \\
\hline No $(\mathrm{N}=89)$ & $39(66.1)$ & $50(84.7)$ & & \\
\hline \multicolumn{5}{|l|}{ Parity } \\
\hline $1-3$ previous-para $(\mathrm{N}=52)$ & $22(37.3)$ & $30(50.8)$ & & 1 \\
\hline Nullipara $(\mathrm{N}=21)$ & $12(20.3)$ & $9(15.3)$ & 0.25 & $1.82(0.65-5.06)$ \\
\hline Multipara (> 3) $(\mathrm{N}=45)$ & $25(42.4)$ & $20(33.9)$ & 0.19 & $1.7(0.76-3.81)$ \\
\hline \multicolumn{5}{|l|}{ Birth weight } \\
\hline Normal $(\mathrm{N}=71)$ & $25(42.4)$ & $46(77.9)$ & & 1 \\
\hline Low BW $(<2500 \mathrm{~g})(\mathrm{N}=16)$ & $8(13.6)$ & $8(13.6)$ & 0.27 & $1.84(0.62-5.49)$ \\
\hline Macrosomia $(\geq 4,000 \mathrm{~g})(\mathrm{N}=31)$ & $26(44.0)$ & $5(8.5)$ & $0.000^{*}$ & $9.57(3.26-28.0)$ \\
\hline \multicolumn{5}{|l|}{ Gestational age (weeks) } \\
\hline Term $(37-41)(\mathrm{N}=91)$ & $42(71.2)$ & $49(83.1)$ & & 1 \\
\hline Preterm $(<37)(\mathrm{N}=19)$ & $12(20.3)$ & $7(11.8)$ & 0.18 & $2.0(0.72-5.54)$ \\
\hline Post-term $(>41)(\mathrm{N}=8)$ & $5(8.5)$ & $3(5.1)$ & 0.38 & $1.94(0.45-8.62)$ \\
\hline \multicolumn{5}{|l|}{ Maternal Hb level } \\
\hline$<11 \mathrm{gm} / \mathrm{dl}(\mathrm{N}=35)$ & $27(45.8)$ & $8(13.6)$ & $0.000^{*}$ & $5.37(2.17-13.3)$ \\
\hline$\geq 11 \mathrm{gm} / \mathrm{dl}(\mathrm{N}=73)$ & $32(54.2)$ & $51(86.4)$ & & \\
\hline \multicolumn{5}{|l|}{ Maternal BMI } \\
\hline Normal $(18-<25)(\mathrm{N}=36)$ & $13(22.0)$ & $25(42.4)$ & & 1 \\
\hline Overweight $(25-\leq 30)(\mathrm{N}=43)$ & $21(35.6)$ & $22(37.3)$ & 0.19 & $1.84(0.75-4.51)$ \\
\hline Obese $(>30)(\mathrm{N}=37)$ & $25(42.4)$ & $12(20.3)$ & $0.005^{*}$ & $4.01(1.53-10.5)$ \\
\hline
\end{tabular}


Table II: Association of PPH with delivery related factors

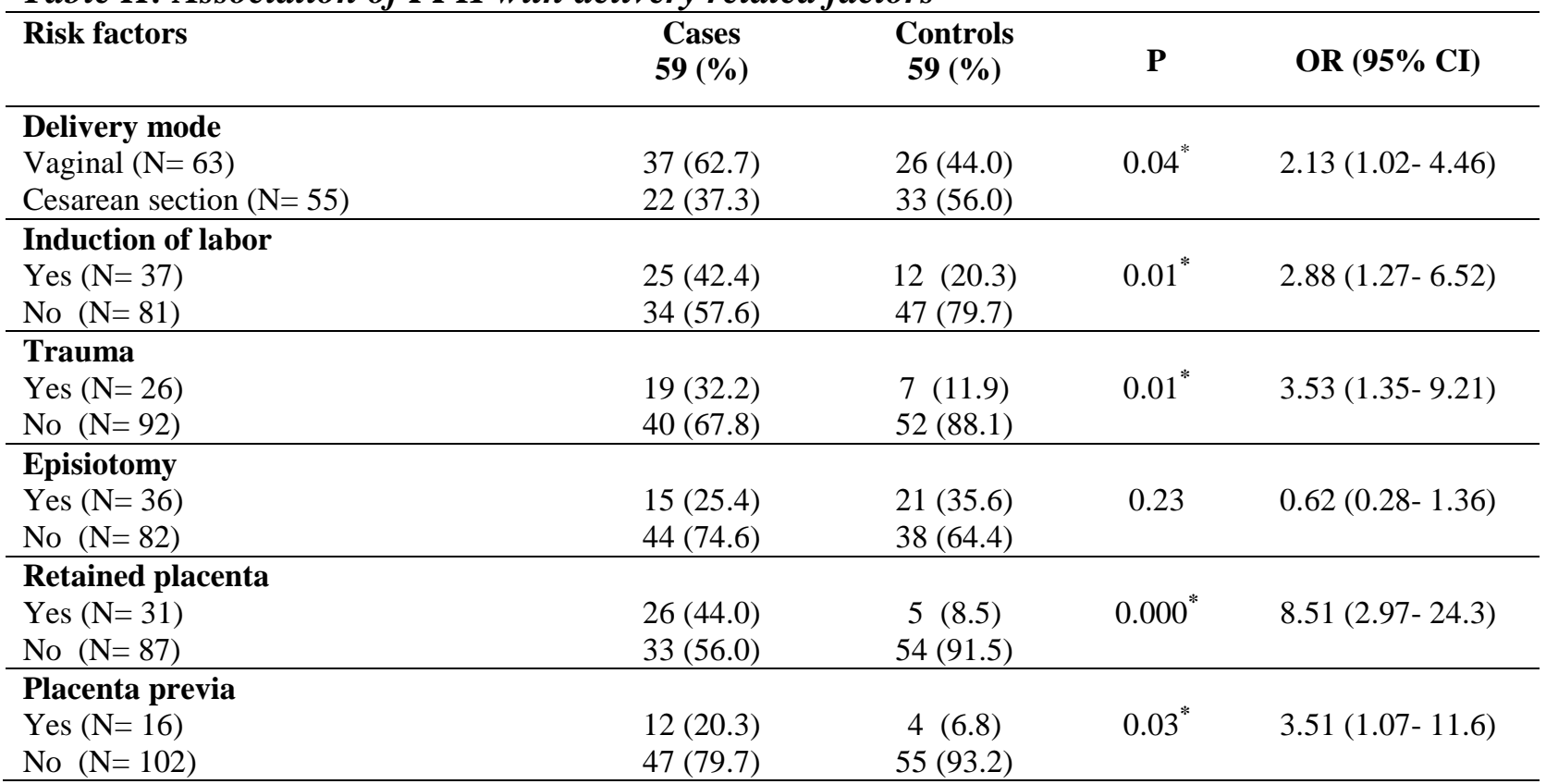

Table III: Stepwise Logistic regression analysis of significant risk factors associated with primary $P P H$

\begin{tabular}{lcccccc}
\hline Risk factors & B & SE & Wald & df & Significance & OR (95\% CI) \\
\hline Hb level $(<\mathbf{1 1 g m} / \mathbf{d I})$ & 2.193 & 0.711 & 9.531 & 1 & $0.002^{*}$ & $0.112(0.03-0.49)$ \\
Retained placenta & 2.428 & 0.799 & 9.221 & 1 & $0.002^{*}$ & $0.088(0.09-0.42)$ \\
Macrosomia & 1.863 & 0.785 & 5.629 & 1 & $0.018^{*}$ & $0.155(0.03-0.72)$ \\
Previous PPH & 1.792 & 0.758 & 5.164 & 1 & $0.023^{*}$ & $0.167(0.04-0.78)$ \\
\hline
\end{tabular}

\section{DISCUSSION}

PPH was considered a public health issue for many years, primarily in low resource countries. ${ }^{[9]}$ In recent years industrialized countries have viewed what seems to be a slow but steady increase in the incidence of $\mathrm{PPH} .^{[1]}$ Our case control study revealed that, the risk for primary PPH was siginificantly increased as maternal age was increasing more than 34 years old (figure 1) in agreement with previous studies ${ }^{[16,17]}$. The majority of studies failed to show a clear impact of aging on $\mathrm{PPH},{ }^{[12,17]}$ while it can be explained by that older mothers had more risks of placenta previa, retained placenta, macrosomia, uterine rupture and other medical complications causing $\mathrm{PPH}^{[18]}$ Agreeing with a previous study, ${ }^{[19]}$ we found that, there was no association between PPH and socioeconomic status, while other studies, ${ }^{[4,2]}$ found that, Low socioeconomic status was associated with increased risk for PPH.

Association of $\mathrm{PPH}$ with previous obstetric and current related factors

Several studies showed that, previous CS was associated with increased risk of PPH. ${ }^{[12,16,21]}$ In contrast, in the present study previous CS was not a risk factor for PPH (Table 1) which was constant with the results of many studies. ${ }^{[17,22,23]}$ Our explanation is that, all women who have had a previous CS must have placental site demonstration by ultrasound that may be protecting from $\mathrm{PPH}$.

Our finding revealing that, prior APH carried a risk for $\mathrm{PPH}(\mathrm{OR}=3.57)$ (Table 1) was 
consistent with other studies had shown the following results; $(\mathrm{OR}=3.8),{ }^{[12]}$ and $(\mathrm{OR}=$ 1.8). ${ }^{[24]}$ In the current study, prior PPH was associated with an increased risk of PPH $(\mathrm{OR}=$ 2.85) (Table 1) in agreement with other studies. ${ }^{[5,25]}$ Also, the prospective cohort study in Egypt, ${ }^{[26]}$ reported that, prior $\mathrm{PPH}$ had a predictive probability of $70 \%$ for incidence of PPH.

Regarding parity, in agreement with several studies, $\left.{ }^{[1,13}, 19,27\right]$ our study revealed that, multiparity was not a risk factor for PPH as multiparous women at Zagazig University Hospitals were treated as a high risk group and managed vigilantly. However, other studies, ${ }^{[28,}$ 29] have reported an association between multiparity and PPH. Also, we did not find an association between nulliparity and PPH which was consistent with previous studies, ${ }^{[13,17]}$ and inconsistent with others. ${ }^{[20,26]}$

We found that, fetal macrosmia was a significant risk factor for $\mathrm{PPH}(\mathrm{OR}=9.57)$ (Table 1) which was cosistent with the following studies' results $(\mathrm{OR}=1.4),{ }^{[13]}(\mathrm{OR}=$ $2.01),{ }^{[30]}$ and $(\mathrm{OR}=2.36) .{ }^{[31]}$ Montreal, ${ }^{[12]}$ Egyptian, ${ }^{[26]}$ and NewZealand studies, ${ }^{[32]}$ also demonstrated an increased risk for $\mathrm{PPH}$ with macrosomia in contrast with others. $\left.{ }^{[17,} 33\right]$ Macrosomia increases agenital trauma and uterine atony by uterine over distention and exhaustion. It is a lifestyle problem needing public health intervention. ${ }^{[34]}$ The occurrence of PPH in our study was not affected by gestational age.

Iron deficiency anemia may weaken uterine muscle or lower resistance to infectious diseases, contributing to $\mathrm{PPH}$ and subsequent mortality. ${ }^{[26,35]}$ In accordance with previous studies our study found a significant association of anemia and PPH $(\mathrm{OR}=5.37)$ (Table 1).

The International Postpartum Hemorrhage Collaborative Group stated a key recommendation to further investigate maternal obesity as a potential risk factor for $\mathrm{PPH} .{ }^{[21]} \mathrm{In}$ the present study, obese women have an increased risk of $\mathrm{PPH}(\mathrm{OR}=4.01)$ (Table 1) regardless of mode of delivery. Several studies were consistent with our results, ${ }^{[18,27]}$ and a population based observational study in UK found that, vaginaly deliverd obese women had higher risk for PPH compared to overweight women $(\mathrm{OR}=1.5){ }^{[36]}$

\section{Association of $\mathrm{PPH}$ with delivery related factors}

The finding in the current study that vaginal deliveries carried the risk for PPH $(\mathrm{OR}=2.13)$ (Table 2) was confirmed in several studies. ${ }^{[18,}$ 37] CS cases were placed under close observation and have early diagnosis of hemorrhage with earlier interventions therefore, planned CS seems to play a protective role against $\mathrm{PPH}{ }^{[38]}$

A potential factor for $\mathrm{PPH}$ is the practice of labor induction that is presently performed more frequent than before. ${ }^{[21,39]}$ In our study, labor induction was a significant risk factor for $\mathrm{PPH}(\mathrm{OR}=2.88)$ (Table 2) in agreement with previous studies showed the following results $(\mathrm{OR}=1.71),{ }^{[23]}(\mathrm{OR}=1.74),{ }^{[31]}$ and $(\mathrm{OR}=$ 1.22). ${ }^{[39]}$ This finding can be explained by that, labor induction may increase duration of labor which may increase frequency of $\mathrm{PPH}$ and also, the drugs inducing labor cause direct uterine contractions, act as a fatigue factor on the uterine muscle leading to postpartum atony and PPH.

Regarding the genital tract trauma, our results demonstrated a significant PPH risk with trauma $(\mathrm{OR}=3.53)$ (Table 2) which was in agreement of previous studies. ${ }^{[13,26]}$ Iatrogenic trauma by the indiscriminate use of a midline or medilateral episiotomy was associated with excessive blood loss and $\mathrm{PPH}$ in two previous studies, ${ }^{[1,13]}$ with the following resluts $(\mathrm{OR}=$ $1.7)$ and $(\mathrm{OR}=1.27)$ respectively. In contrast, we found that episiotomy was not a risk factor for PPH (Table 2) consistantly with the results of other studies. ${ }^{[39,40]}$

Retained placenta accounts for approximately $10 \%$ of all cases of PPH, occurs after $0.5-3 \%$ of deliveries. ${ }^{[41]}$ In the current study, retained placenta had a significant increased risk for PPH $(\mathrm{OR}=8.51)$ (Table 2) in agreement with many studies. ${ }^{[4,17,43]}$ Retained placental 
fragments inhibit adequate uterine contraction and subsequent uterine atony and $\mathrm{PPH} .{ }^{[4]}$

Placenta previa was associated with $\mathrm{PPH}$ $(\mathrm{OR}=12)$ representing the highest of any major risk factor. ${ }^{[23]}$ We found that, placenta previa was a significant risk factor for PPH $(\mathrm{OR}=$ 3.51) (Table 2). The same finding was reported by other studies. ${ }^{[4,12]}$ This finding may be explained by that, placenta previa causes poor myometrial contraction cannot stop bleeding from numerous vessels beneath placental implantation area. ${ }^{[5]}$

Finally, Stepwise logistic regression showed that, maternal anemia, retained placenta, macrosomia, and previous PPH were the most statistical significant risk factors of primary PPH (Table 3).

\section{CONCLUSION}

There are many risk factors for primary $\mathrm{PPH}$ as increasing maternal age, previous APH and PPH, macrosomia, maternal anemia, obesity, vaginal delivery, labor induction, delivery trauma, retained placenta and placenta previa. Maternal anemia, retained placenta, macrosomia, and previous PPH were the most significant risk factors for primary $\mathrm{PPH}$.

\section{RECOMMENDATIONS}

In order to reduce the maternal morbidity and mortality, we recommend properly organized antenatal visits helping early detection of risk factors of PPH and providing an opportunity to educate the women about the risk factors of $\mathrm{PPH}$ and training on active management of the third stage of labour for the prevention and treatment of PPH. Clinicians should identify risk factors before and during labour as early as possible to optimize care for high risk women. Finally, Every health facility should have adequate supplies of uterotonic drugs, equipment and protocols for the prevention and treatment of PPH as well as blood transfusion facilities.

\section{ACKNOWLEDGEMENT}

We would like to show our gratitude to the heads of obstetrics and gynecology department and outpatient clinic who provided general support and assistance during the period of data collection.

The authors declare that there are no conflicts of interest.

\section{REFERENCES}

1- Lutomski J, Byrne B, Devane D, Greene R. Increasing trends in atonic postpartum haemorrhage in Ireland: an 11-year population-based cohort study. BJOG. 2012;(119):306-14.

2- World Health Oragnization. WHO, UNICEF, UNFPA, The World Bank estimates. Trends in maternal mortality: 1990 to 2010 . Genva, World Health Organization, 2012a.

3- World Health Oragnization. WHO recommendations for the prevention and treatment of postpartum hemorrhage Geneva: WHO 2012b.

4- Cunningham FG, Leveno KJ, Bloom SL, Hauth JC, Rouse DJ, Spong CX. Obstetrical hemorrhage chapter 35. In Williams Obstetrics: $23^{\text {rd }}$ ed. New York: McGraw-Hill; 2010:757803.

5- Oyelese Y, Ananth CV. Postpartum hemorrhage: epidemiology, risk factors and causes. Clin. Obstet. Gynecol. 2010;53:147-56.

6- Blomberg M. Maternal obesity and risk of postpartum hemorrhage. Obstet. Gynecol. 2011;118:561-68.

7- Clark SL, Belfort MA, Dildy GA, Herbst MA, Meyers JA, Hankins GD. Maternal death in the 21st century: causes, prevention, and relationship to cesarean delivery. Am. J. Obstet. Gynecol.2008;199(1):91-92.

8- Carroli G, Cuesta C, Abalos E, Gulmezoglu AM. Epidemiology of postpartum hemorrhage: a systematic review. Best Pract Res Clin Obstet Gynaecol 2008;22:999-1012.

9- Global Burden of Disease Mortality and Causes of Death, Collaborators. Global, regional, and national age-sex specific all-cause and causespecific mortality for 240 causes of death, 19902013: a systematic analysis for the Global Burden of Disease Study 2013. Lancet. 2015;385(9963):117-71.

10- Cabero-Roura L, Keith LG. Postpartum hemorrhage: diagnosis, prevention and management. J Matern Fetal Neonatal Med. 2009;22:38-43.

11- Weeks A. The prevention and treatment of postpartum haemorrhage: what do we know, 
and where do we go to next?. BJOG : an international journal of obstetrics and gynecology.2015;122(2):202-10.

12- Kramer MS, Dahhou M, Vallerand D, Liston R, Joseph KS. Risk factors for postpartum hemorrhage: can we explain the recent temporal increase?. J Obstet Gynecol Can. 2011;33:810 19.

13- Sosa CG, Althabe F, Belizan JM, Buekens P. Risk factors for postpartum hemorrhage in vaginal deliveries in a Latin-American population. Obstet Gynecol. 2009;113:1313-19.

14- Fahmy S, El-Sherbini AF. Determining simple parameters for social classifications for health research. Bulletin of the High Institute of Public Health. 1983;13:95-108.

15- Yang YD1, Zhai GR, Yang HX. Factors relevant to newborn birth weight in pregnancy complicated with abnormal glucose metabolism Zhonghua $\mathrm{Fu}$ Chan Ke Za Zhi. 2010 Sep;45(9):646-51.

16- Ohkuchi A, Onagawa T, Usui R, et al. Effect of maternal age on blood loss during parturition: a retrospective multivariate analysis of 10,053 cases. J Perinat Med. 2003;31:209-15.

17- Satapornteera P, Arj-Ong S, Mist MA, Aswakul O. Factors associated with early postpartum hemorrhage of singleton pregnancy in Maharat Nakhou Ratchasima Hospital. Thai. J Obstet Gynecol. 2012;20:21-28.

18- Callaghan WM, Kuklina EV, Berg CJ. Trends in postpartum hemorrhage: United States, 1994-2006. Am J Obstet Gynecol. 2010;202:353:1-6.

19- Selo-Ojeme DO, Okonofua FE. Risk factors for primary postpartum haemorrhage. A case control study. Arch Gynecol Obstet. 1997;259:179-87.

20- Al-Zirqi I, Vangen S, Forsen L, Stray-Pedersen B. Effects of onset of labour and mode of delivery on severe postpartum haemorrhage. Am J Obstet Gynecol. 2009;201:73.

21- Knight M, Callaghan WM, Berg C, Alexander $\mathrm{S}$, Bouvier-Colle MH, Ford JB, et al. Trends in postpartum hemorrhage in high resource countries: a review and recommendations from the International Postpartum Hemorrhage Collaborative Group. BMC Pregnancy and Childbirth. 2009;9:55.

22- Bateman BT, Berman MF, Riley LE, Leffert LR. The epidemiology of postpartum hemorrhage in a large nationwide sample of deliveries. Anesth Analg. 2010;110:1368-73.

23- Royal College of Obstetricians and Gynecologists. Prevention and management of postpartum hemorrhage. RCOG Green-top Guidelines. 2009;No.52. https://www.ranzcog.edu.au/Obstetrics/RCOG.

24- Magann EF, Evans S, Chauhan SP, Lanneau G, Fisk AD, Morrison JC. The length of the third stage -of labor and the risk of postpartum hemorrhage. Obstet Gynecol 2005;105:290-3.

25- Ford JB, Roberts CL, Bell JC. Postpartum haemorrhage occurrence and recurrence: a population-based study. Med J Aust. 2007;187:391-93.

26- Prata N, Hamza S, Bell S, Karosek D, Vahidnia F, Holston M. Inability to predict postpartum hemorrhage: insight from Egyptian intervention data. BMC Pregnancy Childbirth. 2011;11:97.

27- Humphrey MD. Is grand multiparity an independent predictor of pregnancy risk? A retrospective observational study. Med J Aust. 2003;179:294-96.

28- Yousef F, Haider G. Postpartum hemorrhage an experience at tertiary care hospital. J Surg Pak Int. 2009; 14:80-84.

29- Ijaiya MA, Aboyeji AP, Abubakar D. Analysis of 348 consecutive cases of primary postpartum haemorrhage at a tertiary hospital in Nigeria. $\mathbf{J}$ Obstet Gynaecol. 2003;23:374-77.

30- Jolly MC, Sebire NJ, Harris JP, Regan L, Robinson S. Risk factors for macrosomia and its clinical consequences: a study of 350,311 pregnancies. Eur J Obstet Gynecol ReprodBiol. 2003;111:9-14.

31- Magann EF, Evans S, Hutchinson M, Collins R, Howard BC, Morrison JC. Postpartum haemorrhage after vaginal birth: an analysis of risk factors. South Med J. 2005;98:419-22.

32- Fyfe EM, Thompson JMD, Anderson NH, Groom KM, McCowan LM, Maternal obesity and postpartum hemorrhage after vaginal and cesarean delivery among nulliparous women at term. BMC Pregnancy Childbirth. 2012; 18(12):112.

33- Rueang-Chainikhom W, Srisuwan S, Prommas S, Sarapak S. Risk factors for primary postpartum hemorrhage in Bhomibol Adulyade Hospital. J Med Assoc Thai. 2009;92(12):158690. 
34- Henriksen T, The macrosomia fetus, A challenge in current obstetrics. Acta Obstet Gynecol Scand. 2008;87:134.

35- Allen LH. Anemia and iron deficiency: effects on pregnancy outcome. Am J clin Nutr. 2000;71280S-4S.

36- Usha Kiran TS, Hemmadi S, Bethel J, Evans J. Outcome of pregnancy in a woman with an increased body mass index. BJOG 2005;112:768-72.

37- Driessen M, Bouvier-colle MH, Dupont C, Hoshnood B, Rudigoz RC, Deneux-Tharaux C. Postpartum hemorrhage resulting from uterine atony after vaginal delivery: factors associated with severity. Obstet Gynecol. 2011;117:21-31.

38- Chang C-C, Wang I-T, Chen Y-H, Lin H-C. Anesthetic management as a risk factor for postpartum hemorrhage after cesarean deliveries. Am J Obstet Gynecol 2011;205: 462.e1-7.

39- Khireddine I, LeRay C, Dupont C, Rudigoz RC, Bouvier. Colle MH, Deneux-Tharaux C. Induction of labour and risk of postpartum hemorrhage in low risk parturients. PLOS One. 2013;8 e54858.

40- Dannecker C, Hillemanns P, Strauss A, Hasbargen U, Hepp H, Anthuber C. Episiotomy and perineal tears presumed to be imminent: randomized controlled trial. Acta Obstet Gynecol Scand. 2004;83:364-68.

41- Van Beekhuizen HJ, Pembe AB, Fauteck H, Lotgering FK. Treatment of retained placenta with misoprostol: a randomized controlled trial in a low-resource setting (Tanzania). BMC Pregnancy Childbirth. 2009;9:48. 